\title{
Erratum to: Steroid-resistant nephrotic syndrome in a child with dysmorphic features: Questions
}

\author{
Osama Safder • Sherif M. El-Desoky • \\ Detlef Bockenhauer • Neil Sebire • Jameela A. Kari
}

Published online: 6 March 2014

(C) IPNA 2014

\section{Erratum to: Pediatr Nephrol}

DOI: $10.1007 / s 00467-014-2752-4$

There was an error in the authors name of the article

The correct name is: Neil Sebire

Another error was in the legend of Fig. 2.

The correct legend of Fig. 2 is:

Renal biopsy with glomeruli stained with silver stain

The online version of the original article can be found at http://dx.doi.org/ $10.1007 / \mathrm{s} 00467-014-2752-4$.

O. Safder $\cdot$ S. M. El-Desoky $\cdot$ J. A. Kari

Pediatric Nephrology Unit, Department of Pediatrics, Faculty of

Medicine, King Abdulaziz University, Jeddah, Kingdom of Saudi

Arabia

D. Bockenhauer

Renal Unit, University College London, London, UK

N. Sebire

Department of Pathology, Great Ormond Street Hospital, Institute of

Child Health, University College London, London, UK

J. A. Kari $(\bowtie)$

Department of Pediatrics, Faculty of Medicine, King Abdulaziz

University, PO Box 80215, Jeddah 21589, Kingdom of Saudi Arabia

e-mail: jkari@doctors.org.uk 